\title{
Encountering and counselling patients and family members in out-of-hospital emergency care in non-conveyance situations: Follow-up study in Finland
}

\author{
Eija Paavilainen, ${ }^{1,2}$ Riitta Mikkola, ${ }^{1}$ Mari Salminen-Tuomaala, ${ }^{3}$ Päivi Leikkola ${ }^{2}$ \\ ${ }^{1}$ Faculty of Social Sciences, Health Sciences, Nursing Science, University of Tampere; ${ }^{2}$ Hospital District of \\ South Ostrobothnia; ${ }^{3}$ School of Health Care and Social Work, Seinäjoki University of Applied Sciences, \\ Seinäjoki, Finland
}

\begin{abstract}
Rather little is known about emergency care in out-of-hospital settings, for example in patients' homes, where acute situations often emerge and require rapid action from those present. Research evidence concerning the issue is crucial for the development of emergency care services and for responding to patients' and professionals' needs. This study aims to describe how out-of-hospital emergency staff experience encountering and counselling patients and their family members and making non-conveyance decisions after having attended an educational intervention dealing with these issues. Data were collected by electronic questionnaires sent to all out-of-hospital emergency staff members ( $\mathrm{N}=238)$ of a hospital district in Finland in 2014 and in 2016. Data were mainly analyzed using statistical methods. The educational intervention did not affect respondents' self-perceived encountering and counselling skills much, although some positive development was observed. The educational intervention had some positive effect on emergency care providers' encountering and counselling skills. Especially the attention given to family members in care situations
\end{abstract}

Correspondence: Eija Paavilainen, Faculty of Social Sciences, 33014 University of Tampere, Tampere, Finland.

Tel.: +358.40.190.4079.

E-mail: eija.paavilainen@uta.fi

Acknowledgements: the authors especially wish to thank the emergency staff members, who responded to our questionnaire twice, and also participated on the extensive training based on the research results.

Key words: Out-of-hospital emergency care; Follow-up; Counselling.

Contributions: PL, EP, RM, MS-T: study design; PL: data collection; RM: data analysis; EP, PL, RM, MS-T: manuscript preparation.

Conflict of interest: the authors declare no potential conflict of interest.

Funding: this research is supported by a grant from State Research Funding, Finland (VTR21/3011), awarded to the Hospital District of South Ostrobothnia via Pirkanmaa Hospital District.

Received for publication: 7 April 2018.

Revision received: 28 May 2018.

Accepted for publication: 4 June 2018.

This work is licensed under a Creative Commons Attribution 4.0 License (by-nc 4.0).

CCopyright E. Paavilainen et al., 2018

Licensee PAGEPress, Italy

Emergency Care Journal 2018; 14:7468

doi:10.4081/ecj.2018.7468 increased. The training appears to be in the right direction, but it must be continued. The continuously increasing knowledge of patients' and family members' care and counselling experiences also helps staff to understand situations from client perspective, bringing a new dimension to emergency care services.

\section{Introduction}

Emergency care, as a life-saving health care service, has been studied quite extensively worldwide over the past years. ${ }^{1-3}$ However, little is still known about emergency care that takes place in out-of-hospital settings, for example in patients' homes. Acute situations frequently emerge in homes and require rapid action from those who are present to call for help. The most urgent procedures are carried out on site, often in the presence of family members, followed by transport to hospital or by home care based on care providers' instructions. In these situations, it is essential to secure the safest possible care for patients. ${ }^{4,5}$ High quality, situation-specific counselling and especially follow-up care instructions are necessary for the patient to cope at home after the ambulance has left. ${ }^{6,7}$ Care providers generally find that the counselling they provide is of good quality, but that there are challenges, especially as regards the presence of family members, attending to them and supporting them, and also as regards planning and securing followup care. ${ }^{1,6}$ It has been confirmed that post-registration training can be useful in developing nurses' communication skills, ${ }^{8}$ which can be seen to be connected with practicing client-centred counselling. A literature review ${ }^{9}$ revealed that communication skills training can have a positive effect on multiprofessional collaboration, professional support and management of sensitive issues. Another study indicated that a counselling training program might enhance nurses' interaction with patients and families, and consequently improve the quality of care and prevent burnout. ${ }^{10}$ The same issues should now be addressed in the out-of-hospital emergency care context, which differs from the traditional hospital environment.

This study is part of a larger research project carried out in Finland. The project deals with follow-up, evaluation and modelling of out-of-hospital emergency care, which in acute situations often represents a patient's first contact with health services. The project addresses both staff's clinical skills and encountering and counselling of patients and families. Perspectives of patients, family members and care providers are incorporated. The knowledge produced can be used worldwide to systematically develop the quality of emergency care across a wide range of acute situations in out-of-hospital settings. Making the service more family-centred is an important part of the undertaking, because it helps ensure successful home care if the patient is not transported to hospital.

This paper deals with encountering and counselling of patients and family members in out-of-hospital emergency care, including 
decisions not to transport the patient to hospital. Respondents were out-of-hospital emergency staff, who attended an educational intervention addressing these issues. The paper presents follow-up data on the respondents' experiences. The research questions are: i) How do out-of-hospital emergency staff encounter and counsel patients and their family members in acute care situations after having attended an educational intervention addressing these issues? ii) How do they describe their decision-making in non-conveyance situations?

\section{Materials and Methods}

\section{Design and participants}

Two sets of data were collected in a hospital district in Finland in 2014 and in 2016 using electronic questionnaires sent to all outof-hospital emergency staff members $(\mathrm{N}=238)$, which include registered nurses, practical nurses, hospital and ambulance attendants or emergency medical technicians. In the Finnish healthcare system, hospital districts are responsible for providing advanced medical care services, including emergency care, for particular geographical regions. The hospital district involved in this study serves a population of 200, 000. Health services in Finland are divided into primary health care and specialized medical care. Primary health care refers to the municipally arranged monitoring of the health of the population. Primary health care services are provided at municipal health centres. Specialised medical care refers to specialist health examinations and treatment. Most specialised medical care is performed in hospitals. However, concerning emergency care services, the aim is to take care of patients on site or provide a possibility to go to a municipal health care centre when rapid transportation is not necessary.

An educational intervention was conducted between the two data collection phases. It was a one-day (7-hour) course targeted at the whole emergency care staff. The topics addressed were high quality counselling and guidance of patients and family members in acute care situations, where the patient is not transported to hospital; learning from affected couples' experiences and developing current acute care practices; identifying domestic violence in acute care situations; bringing the care situation to a good closure and implementing relevant patient fees. Research permissions and ethical approval were obtained from Pirkanmaa Hospital District Ethics Committee (no. R13164H). Participation was voluntary, based on the respondents' informed consent.

\section{Measures}

The questionnaire used had been specifically developed for this follow-up study. ${ }^{6}$ A group of experts in emergency care; staff, leaders, researchers and a teacher, were requested to contribute to the questionnaire design to improve inter-rater reliability. The instrument was based on elements of high-level encountering and counselling of patients and families, discovered through carefully conducted literature searches..$^{3,11-20}$ Respondents were instructed to start by answering background questions (items 1-8) about their age, sex, qualification, current position, type of employment and about their work experience in the current position, in emergency care and in health service. These questions were followed by 10 statements dealing with encountering and 12 statements dealing with counselling of patients and their family members.

The following two sum variables were formed: Encountering (Introducing oneself; Individual patient contact; Providing information) and Counselling (Psychological support; Understanding instructions; Health promotion and supporting follow-up care; Counselling patients). A 7-point Likert scale was used: $1=$ not part of my role definition; $2=$ totally disagree; 3 =disagree; $4=$ somewhat disagree; $5=$ somewhat agree; $6=$ agree and, $7=$ totally agree. The Cronbach alfas at baseline and follow-up varied between .60 and $.90{ }^{6}$ Values $>.60$ were considered to indicate that the instrument was reliable enough. ${ }^{21}$ The instrument also contained an open question on the difficulty or ease of non-conveyance decision-making and the underlying reasons and challenges.

\section{Data analysis}

Statistical analysis was conducted using Statistical Product and Service Solutions for windows 22.0. Responses to the items on encountering and counselling patients and family members were classified into the following: $0=$ not part of my role definition; $1=$ disagree/totally disagree; $2=$ somewhat disagree; $3=$ somewhat agree; and $4=$ agree/totally agree, with 0 (not part of my role definition) classified as missing information in the final printout. Frequency distributions, means, standard deviation and cross tabulation were used to analyze data. It was ensured during the classification of background variables there was an adequate number of observations in each category and that the categories remained comparable. The overall response rate at baseline was 59\%. The chi-square test $\left(\chi^{2}\right)$ was used to examine statistical associations among variables in cross tabulation. Baseline and follow-up data were compared, but no statistically significant differences were discovered. The differences are presented as percentages to demonstrate the progress that occurred in some items. Responses to the open question were analyzed using inductive content analysis. This involved reading the data carefully for familiarization and reducing, clustering and abstracting the data according to the research question. The number of entries within categories is also presented in the results section. The inter-rater reliability was assured by having one team member conduct the basic analysis, while the other members examined the original data to confirm the analysis. The research team was unanimous over the results.

Demographic data are presented in Table 1. The statements regarding encountering and counselling of patients and family members with percentages of agreement/disagreement are given in Tables 2 and 3 respectively. Comparison by demographic variables (age, work experience etc.) showed no statistically significant differences, so the data are not presented. The reasons given for nonconveyance and the results concerning challenging non-conveyance situations for inquiries I and II can be found in Table 4 There were 425 entries (I:257, II:168) describing the reasons and 354 entries (I: 192, II: 162) describing challenging non-conveyance situations.

\section{Results}

\section{Demographic characteristics}

In the first inquiry in 2014, half and in the second inquiry in 2016, two thirds of the respondents were women. In the first set of data, the under 35 -year-olds constituted $55 \%$ of the respondents; in the second set of data, their proportion was $64 \%$. In both years, approximately $64 \%$ of the care providers represented basic level emergency care, whereas 36\% worked in advanced level emergency care. The share of registered nurses was $61 \%$ in the first and $70 \%$ in the second inquiry. Others were practical nurses, hospital and ambulance attendants or emergency medical technicians (Table 1). 


\section{Encountering patients and family members}

In both inquiries, respondents agreed with the statement that their work was founded on ethical values. The majority (I:94\%/II:96\%) also said that they planned the patient contacts individually. Most respondents $(80 \% / 72 \%)$ reported that they introduced themselves to patients, but fewer of them $(75 \% / 60 \%)$ said that they introduced themselves to family members as well. All respondents explained the patient the reasons for the procedures carried out. Most of them (92\%/95\%) felt that they were able to place themselves in the patient's situation. The majority $(90 \% / 91 \%)$ also said that they knew how to attend to the needs of patients from different cultures. The presence of the patient's family member was found inconvenient by $46 \% / 35 \%$ of the respondents. In both inquiries, practically all respondents said that they made an effort to provide both patients and family members adequate information about the patient's current situation (Table 2).

\section{Counselling patients and family members}

The respondents $(99 \% / 99 \%)$ found their communication skills good. Nearly all of them $(98 \% / 99 \%)$ gave the home care instructions orally. Most respondents $(85 \% / 82 \%)$ also agreed with the statement that they had adequate time to go over the home care instructions and that they $(96 \% / 99 \%)$ could ensure that the patient had understood the instructions. The results were similar (96\%/97\%) for ensuring that family members had understood the instructions. As regards psychological support, $62 \% / 60 \%$ of the respondents thought they had adequate time to support patients and $50 \% / 52 \%$ said that there was adequate time to support family members after having provided emergency care. A greater percentage (76\%/79\%) reported that they provided patients and family members preventive health education. In addition, $84 \% / 88 \%$ of the respondents found that they encouraged family members to participate in the patient's follow-up care. Nearly all respondents $(100 \% / 97 \%)$ ensured that the patient knew where to contact in case of further problems. The majority of them $(72 \% / 68 \%)$ agreed with the statement that arranging follow-up care was challenging (Table 3 ).

\section{Non-conveyance situations}

In the first inquiry, $19 \%$ of the respondents $(n=27)$ found the decision not to transport the patient to hospital difficult. Slightly under $70 \%(\mathrm{n}=95)$ did not find the decision-making difficult and $14 \%(n=20)$ could not say. In the second inquiry, the non-conveyance decision was found difficult by $29 \%(n=25)$ of the respondents. The decision was not difficult for $58 \%(n=50)$, whereas 13 $\%$ of the respondents $(\mathrm{n}=11)$ chose the option cannot say. It was

Table 1. Respondent demographics.

\begin{tabular}{|c|c|c|}
\hline Respondents' background & $\begin{array}{l}\text { Inquiry I } \\
\mathbf{N}(\%)\end{array}$ & $\begin{array}{c}\text { Inquiry II } \\
\mathbf{N}(\%)\end{array}$ \\
\hline $\begin{array}{l}\text { Age }(\mathrm{n}=142, \mathrm{n}=86) \\
\text { Under } 25 \text { years old } \\
25-34 \text { years old } \\
35-44 \text { years old } \\
\text { Over } 45 \text { years old }\end{array}$ & $\begin{array}{l}23(16.2) \\
55(38.7) \\
40(28.2) \\
24(16.9)\end{array}$ & $\begin{array}{l}8(9.3) \\
47(54.7) \\
16(18.6) \\
15(17.4)\end{array}$ \\
\hline $\begin{array}{l}\text { Sex }(n=142, N=86) \\
\text { Female } \\
\text { Male }\end{array}$ & $\begin{array}{l}71(50) \\
71(50)\end{array}$ & $\begin{array}{l}53(61.6) \\
33(38.4)\end{array}$ \\
\hline $\begin{array}{l}\text { Current job }(\mathrm{n}=142, \mathrm{n}=86) \\
\text { Basic level emergency care } \\
\text { Advanced level emergency care }\end{array}$ & $\begin{array}{l}93(65.5) \\
49(34.5)\end{array}$ & $\begin{array}{l}55(64) \\
31(36)\end{array}$ \\
\hline $\begin{array}{l}\text { Qualification }(\mathrm{n}=142, \mathrm{n}=86) \\
\text { Emerg Med Techn/Hospital \& } \\
\text { Ambulance Attendant or practical Nurse } \\
\text { Nurse }\end{array}$ & $\begin{array}{l}56(39.4) \\
86(60.6)\end{array}$ & $\begin{array}{l}26(30.2) \\
60(69.8)\end{array}$ \\
\hline $\begin{array}{l}\text { Employment }(\mathrm{n}=142, \mathrm{n}=86) \\
\text { Permanent } \\
\text { On contract }\end{array}$ & $\begin{array}{l}106(74.6) \\
36(25.4)\end{array}$ & $\begin{array}{l}67(77.9) \\
19(22.1)\end{array}$ \\
\hline $\begin{array}{l}\text { Work experience in current } \\
\text { position }(\mathrm{n}=141, \mathrm{n}=86) \\
\text { Less than } 1.5 \text { years/ } 2 \text { years or less * } \\
1.5 \text { years }-2.4 \text { years/2.1 years- } 3.9 \text { years* } \\
2.5 \text { years or more/ } 4 \text { years or more* }\end{array}$ & $\begin{array}{l}33(23.4) \\
76(53.9) \\
32(22.7)\end{array}$ & $\begin{array}{c}24(27.9) \\
43(50) \\
19(22.1)\end{array}$ \\
\hline $\begin{array}{l}\text { Working experience in health services }(\mathrm{n}=1 \\
\text { Less than } 3 \text { years/4 years or less* } \\
3-8 \text { years/ over } 4 \text { years-10 years* } \\
8 \text { years or more/over } 10 \text { years* }\end{array}$ & $\begin{array}{l}n=86) \\
25(17.8) \\
55(39.3) \\
60(42.9)\end{array}$ & $\begin{array}{l}20(23.3) \\
33(38.4) \\
33(38.4)\end{array}$ \\
\hline
\end{tabular}

Table 2. Encountering patients and family members.

\begin{tabular}{|c|c|c|c|c|}
\hline \multirow[t]{2}{*}{ Encountering patients and family members } & \multicolumn{2}{|c|}{ Inquiry I } & \multicolumn{2}{|c|}{ Inquiry II } \\
\hline & $\begin{array}{c}\text { Disagree* } \\
\text { N (\%) }\end{array}$ & $\begin{array}{l}\text { Agree* } \\
\text { N (\%) }\end{array}$ & $\begin{array}{c}\text { Disagree* } \\
\text { N (\%) }\end{array}$ & $\begin{array}{c}\text { Agree* } \\
\text { N (\%) }\end{array}$ \\
\hline My work is based on ethical values ( $\left.\mathrm{n}=141^{\prime}, \mathrm{n}=86^{\prime \prime}\right)$ & $1(0.7)$ & $140(99.3)$ & $0(0)$ & $86(100)$ \\
\hline I plan each patient contact individually $\left(\mathrm{n}=142^{\prime}, \mathrm{n}=86^{\prime \prime}\right)$ & $8(5.6)$ & $134(94.4)$ & $3(3.5)$ & $83(96.5)$ \\
\hline I introduce myself to the patient $\left(n=142^{\prime}, n=86^{\prime \prime}\right)$ & $28(19.7)$ & $114(80.3)$ & $24(27.9)$ & $62(72.1)$ \\
\hline I introduce myself to the family member $\left(n=142^{\prime}, n=86^{\prime \prime}\right)$ & $35(24.7)$ & $107(75.3)$ & $34(39.5)$ & $52(60.5)$ \\
\hline I explain the patient the reasons for the procedures I carry out ( $\left.n=142^{\prime}, n=86^{\prime \prime}\right)$ & $0(0)$ & $142(100)$ & $0(0)$ & $86(100)$ \\
\hline I am able to put myself in the patient's life situation ( $\left.n=142^{\prime}, n=86^{\prime \prime}\right)$ & $11(7.7)$ & $131(92.3)$ & $4(4.7)$ & $82(95.3)$ \\
\hline I attend to the various needs of patients from different cultures ( $\left.n=142^{\prime}, n=86^{\prime \prime}\right)$ & $14(9.9)$ & $128(90.1)$ & $8(9.3)$ & $78(90.7)$ \\
\hline $\begin{array}{l}\text { The presence of the patient's family is inconvenient for me in the emergency } \\
\text { care situation }\left(n=142^{1}, n=86^{\prime \prime}\right)\end{array}$ & 77 (54.2) & $65(45.8)$ & $56(65.1)$ & $30(34.9)$ \\
\hline $\begin{array}{l}\text { I make an effort to provide the patient enough information about his/her current } \\
\text { condition }\left(n=142^{\prime}, n=86^{\prime \prime}\right)\end{array}$ & $1(0.7)$ & 141 (99.3) & $0(0)$ & $86(100)$ \\
\hline $\begin{array}{l}\text { I make an effort to provide the family member enough information about } \\
\text { the patient's current condition }\left(n=142^{\prime}, n=86^{\prime \prime}\right)\end{array}$ & $1(0.7)$ & $41(99.3)$ & $0(0)$ & $86(100)$ \\
\hline
\end{tabular}

*Disagree: Totally disagree, disagree, somewhat disagree; **Agree: Totally agree, agree, somewhat agree; 'Inquiry I; "Inquiry II. 
also discovered that in the second inquiry, $58.3 \%$ of the 45 -yearold and older respondents found non-conveyance decisions difficult, whereas in the other age groups, the percentage ranged between $6.7 \%$ and $50 \%\left(\mathrm{~N}=75, \mathrm{df}=3,\left(\chi^{2}\right)=8.925, \mathrm{p}=0.30\right)$. No other statistical differences were discovered regarding the background variables.

\section{Reasons for non-conveyance}

An assessment of the patient's care needs resulted in a nonconveyance decision when there was no immediate need for emergency care. In both inquiries, the respondents said that the reason for non-conveyance was that the patient did not require emergency care or transport to hospital (121/65 entries). The care providers described the situations in a similar way in both inquiries, explaining for example that they found that the patient's condition allowed waiting for the following day and then contacting the local health care centre. In these situations, the patient's condition was found stable, with no need for ambulance transport or emergency care procedures or observation during transport. Patients were often advised to use a taxi or their own car or to ask family members to accompany them to seek treatment, for example in the local health care centre. In some cases, the symptoms had already abated and there was no need for transport to hospital. In the second inquiry, there were no more entries describing clients calling the ambulance just to make sure, as a precaution, and no mention about nonconveyance decisions based on the presence of family members.

Treating the patient on site (28/26 entries) was a commonly mentioned reason for non-conveyance decisions. Both sets of data contained care providers' descriptions of how they had found that the treatment on site had been successful and the patient could be left at home. Procedures carried out included pain alleviation, normalization of blood sugar levels and wound care. General assessment of the patient's condition and lifting a fallen patient were mentioned in the first set of data and administration of fever-reducing medication was mentioned in the second inquiry.

In addition, treatment of minor physical injuries and symptoms on site were mentioned in both inquiries (18/14 entries). Examples given by care providers involved the flu, diarrhoea or other gastric disorders and falls that had not caused any major injury. The sec- ond set of data did not contain any blood pressure or respiratory symptoms. Instead it was mentioned that patients were sometimes treated on site because of minor finger fractures, vague ill feeling or because of their unwillingness to be left alone.

The patient's chronic illness or condition was another reason given by care providers for non-conveyance in both inquiries. In these cases, the patient's chronic or prolonged complaint (26/14 entries) had not deteriorated acutely or significantly and did not require prompt transport to hospital. The symptoms had lasted for weeks or months. As examples, the care providers in the first inquiry mentioned chronic gastric problems, constipation, longlasting deterioration of the general condition, prolonged flu and chronic back pain. The second set of data included back, hip, toe or finger pain that had lasted long, sometimes for years, and had not acutely changed. The symptoms were long-lasting and no specific cure could be offered at that stage.

Psychosocial reasons were also mentioned as an explanation for non-conveyance in both sets of data. The patient's loneliness ( $9 / 8$ entries) was one of the psychosocial reasons given by the care providers. According to the respondents, patients sometimes called for an ambulance because they were frustrated and wanted to have help for a prolonged complaint. The patient's insecurity regarding coping at home or learned helplessness were mentioned in the first but not in the second inquiry. In both sets of data, respondents reported that patients sometimes called for help for social reasons. Feeling very lonely, old or intoxicated people yearned for somebody to talk to.

Some patients were not clients of emergency care services, so they were not transported to hospital according to care providers in both inquiries. Users of intoxicants were mentioned as an example (22/7 entries). Strong alcohol intoxication was reported to commonly cause so-called alarms. Still, patients were not seen as clients of emergency care if they refused to be transferred or if they had unnecessarily called the ambulance. Not finding the patient on site and the patient is a client of the police were mentioned as examples in the first inquiry.

\section{Challenges in non-conveyance situations}

Difficulty of reaching a common understanding with the

Table 3. Counselling patients and family members.

\begin{tabular}{|c|c|c|c|c|}
\hline Counselling patients and family members & Inquil & & Inqu & \\
\hline & $\begin{array}{l}\text { Disagree* } \\
\text { N (\%) }\end{array}$ & $\begin{array}{c}\text { Agree* } \\
\text { N (\%) }\end{array}$ & $\begin{array}{c}\text { Disagree* } \\
\text { N (\%) }\end{array}$ & $\begin{array}{l}\text { Agree* } \\
\text { N }(\%)\end{array}$ \\
\hline I have good communication skills ( $\left.\mathrm{n}=142^{1}, \mathrm{n}=86^{\prime \prime}\right)$ & $1(0.7)$ & $141(99.3)$ & $1(1.2)$ & $85(98.8)$ \\
\hline I give the patient's home care instructions orally $\left(n=142,{ }^{\prime} n=85^{\prime \prime}\right)$ & $3(2.1)$ & $139(97.9)$ & $1(1.2)$ & $84(98.8)$ \\
\hline I give the patient's home care instructions in writing $\left(n=141^{\prime}, n=82^{\prime \prime}\right)$ & $128(90.8)$ & $13(9.2)$ & $77(93.9)$ & $5(6.1)$ \\
\hline I have enough time to go over home care instructions with the patient ( $\left.\mathrm{n}=141^{\prime}, \mathrm{n}=85^{\prime \prime}\right)$ & $21(14.9)$ & $120(85.1)$ & $15(17.6)$ & $70(82.4)$ \\
\hline I make sure that the patient has understood the home care instructions $\left(n=141^{\prime}, n=85^{\prime \prime}\right)$ & $5(3.6)$ & $136(96.4)$ & $1(1.2)$ & $84(98.8)$ \\
\hline I make sure that the family member has understood the home care instructions $\left(\mathrm{n}=141^{\prime}, \mathrm{n}=85^{\prime \prime}\right)$ & $6(4.3)$ & $135(95.7)$ & $3(3.5)$ & $82(96.5)$ \\
\hline $\begin{array}{l}\text { I have enough time to support the patient psychologically after the emergency } \\
\text { care situation }\left(n=141^{1}, n=86^{\prime \prime}\right)\end{array}$ & $53(37.6)$ & 88 (62.4) & 35 (40.7) & $51(59.3)$ \\
\hline I have enough time to support the family member psychologically ( $\left.n=142^{\prime}, n=86^{\prime \prime}\right)$ & $71(50)$ & $71(50)$ & $41(47.7)$ & $45(52.3)$ \\
\hline I provide preventive health education for the patient $\left(n=142^{\prime}, n=85^{\prime \prime}\right)$ & $34(23.9)$ & $108(76.1)$ & $18(21.2)$ & $67(78.8)$ \\
\hline I encourage the family member to participate in the patient's follow-up care $\left(n=141^{\prime}, n=84^{\prime \prime}\right)$ & $23(16.3)$ & $118(83.7)$ & $10(11.9)$ & $74(88.1)$ \\
\hline I make sure that the patient knows where to contact in case of further problems ( $n=141^{\prime}, n=86^{\prime \prime}$ ) & $0(0)$ & $141(100)$ & $3(3.5)$ & $83(96.5)$ \\
\hline I often find arranging follow-up care challenging $\left(n=139^{\prime}, n=85^{\prime \prime}\right)$ & $39(28.1)$ & $100(71.9)$ & $27(31.8)$ & $58(68.2)$ \\
\hline
\end{tabular}

*Disagree: Totally disagree, disagree, somewhat disagree; **Agree: Totally agree, agree, somewhat agree; 'Inquiry I; "Inquiry II. 
patient and/or family member about the non-conveyance decisions was experienced as the greatest challenge (72/73 entries). The patient and/or the family member disagreed about the decision not to transport the patient to hospital; one or both of them had a different perception about the necessity of transport compared to the care providers and sometimes failed to understand why transport was not arranged, even if treatment had been provided on site. Respondents sometimes felt pressured when transport was demanded, even though there was no medical need for it.

In the first inquiry, respondents reported that some patients and family members believed that an ambulance patient was treated more promptly than other patients and could jump in line. The second set of data contained the examples that family members sometimes did not want to assume responsibility for the patient or the family member was experienced as difficult. Care providers occasionally felt that clients tried to put the blame on them or threatened them with a formal complaint. In both inquiries, respondents reported difficulties in reaching a common understanding with patients who required special attention. This group involved confused and aggressive patients and users of intoxicants.

Concern about the patient's coping at home (21/13 entries) was experienced as another challenge in non-conveyance situations. Sometimes care providers found that patients did not necessarily require hospital care, but their coping at home was compromised. It was not always clear if patients would cope at home or if their condition would be observed and if there was a family member, who was able to assume responsibility for the patient's care. Care providers were mostly concerned about aged patients. In the second inquiry, respondents mentioned adequate informing and explaining care decisions to patients as challenges. Care providers also reflected on society's responsibility for the patient's care.

The care providers' responsibility and insecurity about the decisions made emerged from the first set of data. The responsibility was seen to involve an association between patient assessment, examination, diagnostics and non-conveyance decisions. As an example it was mentioned that insecurity was induced in situations, in which patients called for help a second time. Both sets of data contained examples of insecurity caused by the care providers' worry that the patient might not have understood the home care and follow-up care instructions (24/10 entries). Insecurity was also reported if the patient's symptoms were ambiguous (6/4 entries). Other challenges involved the concern about how follow-up/home care would be arranged, for example if the patient would receive adequate help from the home help services. In the first inquiry, care providers described their worry and fears concerning the decision to leave the patient at home; it seemed possible that despite careful examination and treatment the patient might deteriorate. The second inquiry was different from the first in that hospital transport as a precaution was no more mentioned as a potential practice.

In both inquiries, Collaboration between professionals was mentioned as a challenge in non-conveyance situations. Care providers collaborate with emergency physicians, consulting them on patients' situation. Respondents reported that the doctor did not always concentrate adequately on the patient's current situation (9/17 entries). Uncertainty about the doctor's entries into the patient information system was mentioned as a challenge in the first inquiry. The doctor's lacking skills in Finnish language, difficulty of describing the overall situation to the doctor, the doctor's irritation and disagreement with care providers were among the challenges mentioned in the second inquiry (Table 4).

\section{Discussion}

The results show that an educational intervention did not change respondents' perceptions of their encountering and counselling skills much. This might be explained by care providers' high baseline skills or by the assumption that changes occur relatively slowly. ${ }^{8,22}$ Some changes were, however, observed. They are discussed below.

Compared to the first inquiry, a slightly higher proportion of respondents felt more empathy towards the patient's situation and took the patient's cultural background into consideration in the second inquiry. Experiencing the presence of family members in the care situation as inconvenient was less common, which may indicate care providers' increased awareness of the importance of family members and their agreement that family members should be involved in the care. ${ }^{23-25} \mathrm{~A}$ great deal of attention had been given to these issues in the educational intervention, which might explain the development of care providers' situational awareness.

In contrast, introducing oneself to the patient and family members became less common after the intervention. This might be explained by the recent efforts to protect care providers from threatening situations and violence ${ }^{26}$ in emergency services and onduty care; more focus is being placed on this issue in occupational safety. The Act on the Status and Rights of Patients ${ }^{27}$ in Finland, however, states that patients have the right to know who treats them. A fair solution should be found that takes all parties' needs into consideration. The experience of having adequate time for giving home care instructions had become less common, but it was more common for care providers in the second inquiry to ensure that the patient and family member had understood the instructions. In care providers' experience, a little less time was used for supporting the patient psychologically, whereas more time was used for supporting family members and encouraging them to participate in the patient's follow-up care. Care providers also found arranging follow-up care less challenging in the second inquiry. The results were mostly similar in both inquiries for non-conveyance reasons and for the following challenges in non-conveyance situations: reaching mutual understanding, patient's coping at home and collaboration between professionals. It is important for care providers to clearly and comprehensibly explain patients and family members the reasons for not transporting the patient to hospital. It creates trust, which can help families cope better at home. The changes following the educational intervention are mostly in the right direction. This means that the contents of the intervention were appropriate, so similar training should be continued. One might also propose that the inquiries and educational intervention made respondents reflect on their encountering and counselling skills more critically. They probably thought more about how they acted in various situations and what kind of decisions they made regarding patient's care and conveyance. The continuously increasing knowledge of patients' and family members' care and counselling experiences also helps staff to understand situations from client perspective, bringing a new dimension to emergency care.

\section{Limitations of the study}

Low response rates are typical of email surveys. In this study, the challenge was tackled by writing a motivating cover letter and by sending reminders to potential respondents at both baseline and follow-up. The low response rate despite these measures may be due to the fact that the questionnaire was not directly available but required opening a link. It was possibly not clear to respondents why data were collected a second time using the same question- 
naire- hence the lower response rate in the second inquiry. ${ }^{28}$ The educational intervention covered the whole staff, which can be considered an advantage. Mainly the same respondents participated in the two inquiries. It is still possible that there were new respondents in the second phase, which weakens the change eval- uation. The fact that data were collected in one hospital district increases the reliability of the study but may reduce the generalizability of the results. In any case, the results can be used to address and develop the quality of emergency care services in various contexts, also internationally.

Table 4. Reasons for not conveying the patient to hospital and challenges in non-conveyance situations, inquiries I and II.

\begin{tabular}{|c|c|c|}
\hline Sub-category & Generic category & Main category \\
\hline $\begin{array}{l}\text { No need for ambulance transport or emergency care } \\
\text { Data I and II }\end{array}$ & \multirow[t]{3}{*}{ Assessment of care needs } & \multirow[t]{16}{*}{ Reasons for non-conveyance } \\
\hline $\begin{array}{l}\text { Calling the ambulance as a precaution } \\
\text { Data I }\end{array}$ & & \\
\hline $\begin{array}{l}\text { Patient is not left alone at home } \\
\text { Data I }\end{array}$ & & \\
\hline $\begin{array}{l}\text { Treatment provided on site } \\
\text { Data I and II }\end{array}$ & \multirow[t]{3}{*}{ Patient treated on site } & \\
\hline $\begin{array}{l}\text { Minor injury, disease or symptom } \\
\text { Data I and II }\end{array}$ & & \\
\hline $\begin{array}{l}\text { Chronic or prolonged complaint/ old complaint } \\
\text { Data I and II }\end{array}$ & & \\
\hline $\begin{array}{l}\text { Loneliness } \\
\text { Data I and II }\end{array}$ & \multirow[t]{4}{*}{ Psychosocial reasons } & \\
\hline $\begin{array}{l}\text { Insecurity } \\
\text { Data I }\end{array}$ & & \\
\hline $\begin{array}{l}\text { Social reasons } \\
\text { Data I and II }\end{array}$ & & \\
\hline $\begin{array}{l}\text { Learned helplessness } \\
\text { Data I }\end{array}$ & & \\
\hline $\begin{array}{l}\text { Intoxicants } \\
\text { Data I and II }\end{array}$ & \multirow[t]{6}{*}{ Patient is not a client of emergency care services } & \\
\hline $\begin{array}{l}\text { Unnecessary calls } \\
\text { Data I and II }\end{array}$ & & \\
\hline $\begin{array}{l}\text { Patient refuses transport } \\
\text { Data I and II }\end{array}$ & & \\
\hline $\begin{array}{l}\text { Patient is a client of the police } \\
\text { Data I }\end{array}$ & & \\
\hline $\begin{array}{l}\text { Patient cannot be found } \\
\text { Data I }\end{array}$ & & \\
\hline $\begin{array}{l}\text { Other transportation is used } \\
\text { Data I and II }\end{array}$ & & \\
\hline
\end{tabular}
non-conveyance with the patient and family member Data I and II

Patient does not need emergency care or transport to hospital Data I

Problems related to transport

Data I and II

Patient needs special attention

Data I and II

Uncertainty about the patient's coping at home Patient's coping at home

Data I and II

Care provider's responsibility for non-conveyance decisions

Data I

Help from home help services

Data I and II

Collaboration with the emergency physician

Data I and II

Collaboration between professionals

Calling to emergency clinic

Data I 


\section{Conclusions}

The educational intervention had some positive effect on emergency care providers' encountering and counselling skills. Especially attention given to family members in care situations increased, which is an important point in the development of emergency services in general and in prehospital care especially. The training appears to be in the right direction, but it must be continued. The continuously increasing knowledge of patients' and family members' care and counselling experiences also helps staff to understand situations from client perspective, bringing a new dimension to emergency care.

\section{References}

1. Zavala S, Shaffer C. Do patients understand discharge instructions? J Emer Nurs 2011;37:138-40.

2. Paavilainen E, Salminen-Tuomaala M, Leikkola P. Counselling for patients and family members: a follow-up study in the emergency department. ISRN Nurs 2012;303790 [Epub], DOI:10.5402/2012/303790.

3. Mikkola, R. Henkilökunnan kokema pelko ja selviytymiskeinot ensiapupoliklinikoilla: malli pelosta selviytymisestä. [Experiences of fear and coping strategies among staff in emergency departments: model for coping with fear.] $\mathrm{PhD}$ Thesis. University of Tampere, Finland, 2013. Available from: http://urn.fi/URN:ISBN:978-951-44-9137-5

4. Salminen-Tuomaala M, Leikkola P, Paavilainen E. Patient and staff safety incidents and near misses in out-of-hospital emergency care. Emerg Med Open Access 2014;4:5.

5. Ebben R, Vloet L, Speijers R, et al. A patient-safety and professional perspective on non-conveyance in ambulance care: a systematic review. Scand J Trauma Resusc Emerg Med 2017; 25:71.

6. Paavilainen E, Mikkola R, Salminen-Tuomaala M, et al. Counselling patients and family members in out-of-hospital emergency situations: a survey for emergency staff. BMC Nurs 2017; 16:11.

7. Salminen-Tuomaala M, Leikkola P, Mikkola R, et al. Factors that influence the counselling of family members in out-ofhospital emergency medical care. Fam Med Sci Res 2015;4:5.

8. Bowles N, Macintosh C, Torn A. Nurses' communications skills: an evaluation of the impact of solution-focused communication training. J Adv Nurs 2001;36:347-54.

9. Chant S, Jenkinson T, Randle J, et al. Communication skills training in healthcare: a review of the literature. Nurse Edu Today 2002;22:189-202.

10. Arranz P, Ulla S, Ramos J, et al. Evaluation of a counselling training program for nursing staff. Patient Educ Couns 2005;56:233-9.

11. Badir A, Sepit D. Family presence during CPR: a study of the experiences and opinions of Turkish critical care nurses. Int J Nurs Stud 2007;44:83-92.
12. Bernard SA, Nguyen V, Cameron P, et al. Prehospital rapid sequence intubation improves functional outcome for patients with severe traumatic brain injury: a randomized controlled trial. Ann Surg 2010;252:959-65.

13. Campeau A. Why paramedics require 'Theories-of-Practice'. AJP 2012;6. Available from: http://ro.ecu.edu.au/cgi/viewcontent.cgi?article $=1294 \&$ context $=$ jephc. Accessed: 26 January 2015.

14. Deakin CD, King P, Thompson F. Prehospital advanced airway management by ambulance technicians and paramedics: is clinical practice sufficient to maintain skills? Emerg Med J 2009;26:888-91.

15. Evans R, McGovern R, Birch J, et al. Which extended paramedic skills are making an impact in emergency care and can be related to the UK paramedic system? A systematic review of the literature. Emerg Med J 2013;1-10.

16. Hjälte L, Björn-Ove S, Herlitz J, et al. Why are people without medical needs transported by ambulance? A study of indications for pre-hospital care. Eur J Emerg Med 2007;14:151-6.

17. Mason S, Knowles E, Freeman J, et al. Safety of paramedics with extended skills. Acad Emerg Med 2008;15:607-12.

18. Nirel N, Goldwag R, Feigenberg Z, et al. Stress, work overload, burnout, and satisfaction among paramedics in Israel. Prehosp Disaster Med 2008;23:537-46.

19. O'Meara PF, Tourle V, Stringling C, et al. Extending the paramedic in the rural Australia: a story of flexibility and innovation. Rural Remote Health 2012;12. Available from: http://www.rrh.org.au/articles/subviewaust.asp ArticleID: 1978. Accessed: 26 January 2015.

20. Woollard M. The role of the paramedic practitioner in the UK. AJP 2006;4. Available from: http://ro.ecu.edu.au/cgi/viewcontent.cgi? article $=1189 \&$ context $=$ jephc. Accessed 26 January 2015.

21. Burns N, Grove SK. The practice of nursing research: conduct, critique \& utilization. 5th ed. St. Louis, MO: Elsevier Saunders; 2005.

22. Paavilainen E, Salminen-Tuomaala M. Web-based learning environment as a means for continuing nursing education in hospital: the course implemented for emergency unit staff. J Nurses Staff Dev 2010;26:159-63.

23. Paavilainen E, Salminen-Tuomaala M, Kurikka S, et al. Experiences of counselling in the emergency department during the waiting period: importance of family participation. $\mathrm{J}$ Clin Nurs 2009;18:2217-24.

24. Nikki L, Lepistö S, Paavilainen E. Experiences of family members of elderly patients in the emergency department: a qualitative study. Int Emerg Nurs 2012;20:193-200.

25. Raitanen K, Kylmä J, Paavilainen E. Short-term patient and family counselling for acute health change -an integrative literature review. Clin Nurs Stud 2015;3:96-104.

26. Crilly J, Chaboyer W, Creedy D. Violence towards emergency department nurses by patients. Accid Emerg Nurs 2004;12:6773.

27. Act on the Status and Rights of Patients 785/1992. Available from: http://www.finlex.fi/en/

28. Baruch Y, Brooks C. Survey response rate levels and trends in organizational research. Hum Relat 2008;61:1139-60. 